NASA/TM-2001-210593

\title{
A Comparison of Brayton and Stirling Space Nuclear Power Systems for Power Levels from 1 Kilowatt to 10 Megawatts
}

Lee S. Mason

Glenn Research Center, Cleveland, Ohio 
Since its founding, NASA has been dedicated to the advancement of aeronautics and space science. The NASA Scientific and Technical Information (STI) Program Office plays a key part in helping NASA maintain this important role.

The NASA STI Program Office is operated by Langley Research Center, the Lead Center for NASA's scientific and technical information. The NASA STI Program Office provides access to the NASA STI Database, the largest collection of aeronautical and space science STI in the world. The Program Office is also NASA's institutional mechanism for disseminating the results of its research and development activities. These results are published by NASA in the NASA STI Report Series, which includes the following report types:

- TECHNICAL PUBLICATION. Reports of completed research or a major significant phase of research that present the results of NASA programs and include extensive data or theoretical analysis. Includes compilations of significant scientific and technical data and information deemed to be of continuing reference value. NASA's counterpart of peerreviewed formal professional papers but has less stringent limitations on manuscript length and extent of graphic presentations.

- TECHNICAL MEMORANDUM. Scientific and technical findings that are preliminary or of specialized interest, e.g., quick release reports, working papers, and bibliographies that contain minimal annotation. Does not contain extensive analysis.

- CONTRACTOR REPORT. Scientific and technical findings by NASA-sponsored contractors and grantees.
- CONFERENCE PUBLICATION. Collected papers from scientific and technical conferences, symposia, seminars, or other meetings sponsored or cosponsored by NASA.

- SPECIAl PUBLICATION. Scientific, technical, or historical information from NASA programs, projects, and missions, often concerned with subjects having substantial public interest.

- TECHNICAL TRANSLATION. Englishlanguage translations of foreign scientific and technical material pertinent to NASA's mission.

Specialized services that complement the STI Program Office's diverse offerings include creating custom thesauri, building customized data bases, organizing and publishing research results ... even providing videos.

For more information about the NASA STI Program Office, see the following:

- Access the NASA STI Program Home Page at http://www.sti.nasa.gov

- E-mail your question via the Internet to help@sti.nasa.gov

- Fax your question to the NASA Access Help Desk at 301-621-0134

- Telephone the NASA Access Help Desk at 301-621-0390

- Write to:

NASA Access Help Desk

NASA Center for AeroSpace Information 7121 Standard Drive

Hanover, MD 21076 
NASA/TM-2001-210593

\section{A Comparison of Brayton and Stirling Space Nuclear Power Systems for Power Levels from 1 Kilowatt to 10 Megawatts}

Lee S. Mason

Glenn Research Center, Cleveland, Ohio

Prepared for the

Space Technology and Applications International Forum

sponsored by The Institute for Space and Nuclear Power Studies

Albuquerque, New Mexico, February 11-14, 2001

National Aeronautics and

Space Administration

Glenn Research Center 
This report contains preliminary findings, subject to revision as analysis proceeds.

Available from

NASA Center for Aerospace Information 7121 Standard Drive

Hanover, MD 21076

Price Code: A03
National Technical Information Service 5285 Port Royal Road Springfield, VA 22100

Price Code: A03 


\title{
A Comparison of Brayton and Stirling Space Nuclear Power for Power Levels from 1 Kilowatt to 10 Megawatts
}

\author{
Lee S. Mason \\ National Aeronautics and Space Administration \\ Glenn Research Center \\ Cleveland, Ohio 44135
}

\begin{abstract}
An analytical study was conducted to assess the performance and mass of Brayton and Stirling nuclear power systems for a wide range of future NASA space exploration missions. The power levels and design concepts were based on three different mission classes. Isotope systems, with power levels from 1 to 10 kilowatts, were considered for planetary surface rovers and robotic science. Reactor power systems for planetary surface outposts and bases were evaluated from 10 to 500 kilowatts. Finally, reactor power systems in the range from 100 kilowatts to 10 megawatts were assessed for advanced propulsion applications. The analysis also examined the effect of advanced component technology on system performance. The advanced technologies included high temperature materials, lightweight radiators, and high voltage power management and distribution.
\end{abstract}

\section{INTRODUCTION}

A key objective of future NASA missions is to expand human presence into the solar system. In order to satisfy the demanding power requirements of these missions, designers must look beyond conventional photovoltaic and battery power systems. Mission lifetimes will be longer, power levels will be higher, and environmental conditions will be more severe. Robotic precursor systems will be expected to survive between two and five years, while systems for Human missions may be required to operate ten to fifteen years. Sophisticated science instruments and high-rate communication systems may drive power levels on landers and rovers into the multi-kilowatt class. Hundreds of kilowatts may be needed to meet the demands of in-situ resource utilization and closed loop life support for human surface missions. Advanced transportation technologies, such as electric propulsion, may cause spacecraft power systems to surpass megawatt levels. Operating environments will be marked by reduced solar flux, long night periods, dust and wind storms, and dramatic temperature extremes.

One potential solution is nuclear dynamic power conversion. Technology options include Brayton, Stirling, and Rankine cycle heat engines. Dynamic systems are different from static systems in that they include moving parts, such as rotors or pistons and contain a fluid which undergoes state changes to produce thermodynamic work. Many of the space dynamic power system concepts are derived from terrestrial analogs. Brayton technology is commonly used in aircraft auxiliary power units, marine propulsion, and small utility power plants. Stirling technology is used in cryocoolers, residential cogeneration, and solar dish electric systems. Rankine technology is the basis for the majority of the world's steam power plants. The common characteristics of these terrestrial systems are long life, high reliability, and high power density. These same traits are desirable in space power applications.

This paper examines the performance and mass of Brayton and Stirling space power systems for a wide range of power levels and mission applications, while considering the impact of advanced supporting technologies, such as high temperature materials and lightweight radiators. Rankine was not considered in the study since Brayton and Stirling technologies are believed to offer greater technical maturity and reduced complexity. Technology development in Rankine systems was active during the 1960's, but has received little attention since. Rankine systems also introduce the complexity of two-phase fluid management which may be difficult in micro-gravity. Brayton technology development was active in the 1970's and underwent a rebirth in the 1990's with the Solar 
Dynamic Ground and Flight Test Demonstrations. Stirling technology development was active in the 1980's during the SP-100 Space Reactor Program, and is experiencing a resurgence under DOE's Advanced Radioisotope Power System (ARPS) program. Heat source options that were considered in the study include both radioisotope (Pu-238) General Purpose Heat Source (GPHS) modules and liquid-metal cooled nuclear reactors (i.e. SP-100). Other reactor options, including gas-cooled or heat-pipe cooled concepts, are not believed to dramatically effect the overall performance trends.

\section{MISSION CLASSES}

The study examined three classes of mission applications: 1) rovers and robotic science, 2) surface outposts and bases, and 3) spacecraft power and propulsion. Each class included an appropriate power level range and a set of system design ground rules corresponding with the application.

Rovers and Robotic Science - Robotic science missions will serve as a precursor to human missions for site surveying, engineering data gathering, and technology demonstration. These missions will include orbiters for global mapping, landers for localized science, and rovers for regional reconnaissance. Several near term, outer planet missions will utilize radioisotope power systems in the multi-hundred watt class. As the science objectives are expanded and Mars surface missions are contemplated, power requirements are expected to increase. Candidate applications include science rovers for Mars polar missions to search for evidence of water, remote science packages including drills, sample return missions, and ultimately, rovers for piloted surface transportation. Power levels are projected into the 1 to 10 kilowatt range. A radioisotope heat source was assumed for these mission applications, although the cost and availability of $\mathrm{Pu}-238$ for these power levels must be deliberated.

Surface Outposts and Bases - The outpost will be the initial human emplacement and will include landers, habitats, and resource pilot plants. Two primary options exist for power generation: 1) smaller, dedicated systems for each element, or 2) a centralized system that serves multiple elements. The centralized system is favored to minimize mass and allow for outpost evolution. Aggregate power requirements for the surface outpost are in the 10 to 100 kilowatt range. Follow-on surface bases will establish a semi-permanent or permanent human presence. These missions will include scientific laboratories, habitats with closed loop life support, and resource production plants. Power levels will grow into the multi-hundred kilowatt range. Reactors are the preferred heat source for this power range and application.

Spacecraft Power and Propulsion - Future robotic and human missions will rely heavily on advanced propulsion technologies to improve payload fraction and trip time. Electric propulsion systems can provide large propellant mass savings over chemical systems due to their very high specific impulse, but require considerably more spacecraft power. Power levels associated with nuclear electric propulsion (NEP) vehicles will range from less than 100 kilowatts for small robotic science missions to multi-megawatts for large Mars human/cargo missions. Nuclear Thermal Rocket (NTR) technology also offers significant performance advantages over chemical propulsion systems due to the combination of high specific impulse and high thrust. The benefits are enhanced through a bimodal configuration that utilizes the same reactor core for both propulsion and electric power generation. These systems would all utilize reactor heat sources.

\section{TECHNOLOGY OPTIONS}

There are many possible power technologies that can be considered for these mission applications. Solar photovoltaic (PV) and battery systems are the state-of-the-art, used in the majority of space missions. However, the high power and long lifetime requirements of these future missions combined with the severe operating environments (minimal sunlight, dust and wind storms, etc.) result in pronounced mass, volume, and deployed area penalties for solar power systems relative to nuclear.

Nuclear power conversion options are abundant. Static conversion technologies include Alkali-Metal Thermal-toElectric Conversion (AMTEC), thermoelectrics (e.g. Radioisotope Thermoelectric Generators, RTGs), and thermionics. AMTEC was the original power conversion technology for the ARPS program, but was recently 
discontinued in favor of Stirling due to slow progress on the flight system design. Thermoelectrics are a proven, low-risk technology, but suffer from very low conversion efficiency requiring large quantities of Pu-238. Thermionics were used extensively in the Russian TOPAZ reactors, but are also performance and life limiting. The dynamic conversion technology options, Brayton, Stirling, and Rankine offer a superior combination of high efficiency, long life, low mass and durability. As stated earlier, Rankine was not considered in this study based on its lower relative maturity and higher operational complexity.

\section{BRAYTON AND STIRLING HERITAGE}

Space Brayton technology was introduced in the late 1960's under the Brayton Rotating Unit (BRU) development program. The objective was to design, build, and test a 10.5 kilowatt Brayton conversion system that could be used with either a solar heat receiver or isotope heat source (Davis, 1972). Four separate units were built and tested, compiling over 40,000 hours of operation. The BRU program was followed closely by the Brayton Isotope Power System (BIPS) program in the mid-1970's. Under BIPS, a 1.3 kilowatt mini-Brayton Rotating Unit (mini-BRU) and recuperator was developed for isotope power applications (McCormick, 1978). The scaled version incorporated advanced foil bearings and internal stator cooling for greater reliability and simplicity. The mini-BRU was successfully tested for 1000 hours during the BIPS program. During the 1980's Space Station Freedom (SSF) program, a 25 kilowatt Brayton Solar Dynamic Power Module underwent significant design and component development before the program was cancelled (Staff, 1993). That design was the basis for the 1990's 2 kilowatt Solar Dynamic Ground Test Demonstration (SD GTD), which utilized the mini-BRU components combined with SSF derived designs for the concentrator, receiver, and radiator and compiled 800 hours of operation in a thermalvacuum environment (Shaltens, 1999). A flight version of the 2 kilowatt solar Brayton was nearly completed for a 1998 demonstration on the Mir space station, but was cancelled due to Shuttle manifest changes.

Free-piston Stirling technology for space applications underwent extensive development during the 1980's SP-100 Space Reactor Program. The objective was to develop a high performance conversion technology for 100 kilowatt class nuclear reactor power systems. The Space Power Demonstrator Engine (SPDE) was a 25 kilowatt Stirling engine built in 1984, which included two opposed 12.5 kilowatt convertors connected at the hot-end with a common expansion space (Dochet, 1993). After initial demonstration, the two convertors were separated and accumulated over 400 hours of total operation. That effort was followed in the late 1980's with the development of the single cylinder, 12.5 kilowatt Component Test Power Convertor (CTPC) which incorporated new materials and a heat pipe heater head configuration to increase hot-end temperature (Dhar, 1999). The CTPC underwent successful testing and compiled 1500 hours of total operation with an inertial mass balancer. Stirling technology experienced a temporary hiatus until the late 1990's with the development of the 55 watt Technology Demonstrator Convertor (TDC). The TDC is a compact, high efficiency convertor designed to be used in an opposed pair configuration for GPHS radioisotope power applications. Extensive performance, vibration, and electromagnetic interference (EMI) testing was conducted on the TDC before it was selected as the baseline conversion system for ARPS and a proposed 2006 flight on the Europa Orbiter mission (Thieme, 2000).

\section{ANALYTICAL APPROACH}

An Excel spreadsheet model, NUCOPT (Nuclear Optimization) has been developed to perform preliminary design and sensitivity studies of Brayton and Stirling nuclear power systems. The model accounts for all the major subsystems: heat source, power conversion, heat rejection, and power management and distribution (PMAD). Both radioisotope (GPHS) and fast spectrum, liquid-metal cooled reactor (LMCR) heat sources can be evaluated. The LMCR algorithms are derived from the Sandia National Laboratory model, RSMASS (Marshall, 1991). Nuclear reactor shielding can be determined for either instrument-rated dose constraints using RSMASS, or crew-rated dose constraints, based on curve fits of previous Monte-Carlo Neutron Proton (MCNP) calculations. The power conversion algorithms solve thermodynamic equations and utilize a combination of curve fits and scaling laws to determine mass and performance. Waste heat rejection is based on Stefan-Boltzmann radiation heat transfer. The PMAD algorithms, based on models developed by Rocketdyne (Metcalf, 1992), determine the mass of the power conditioning electronics and transmission cabling as a function of source and load voltage specifications. 
NUCOPT provides the capability to determine minimum system mass through an optimization process that considers several design variables. A critical optimization variable for dynamic power systems is cycle temperature ratio or "Trat" (defined as the ratio of maximum cycle temperature to minimum cycle temperature). An optimum temperature ratio results from the trade-off of heat source mass and radiator mass. A larger "Trat" results in high efficiency and a smaller relative heat source, but a lower heat rejection temperature and larger radiator. A smaller "Trat" yields a high heat rejection temperature to reduce radiator size at the expense of lower efficiency and a more massive heat source. Several other design variables associated with the reactor, shielding and PMAD components were also considered in the optimization process.

The radioisotope heat source used in the study is based on the GPHS module with a primary heat exchanger that either radiatively couples the heat source to the power conversion (Stirling) or allows the working fluid to flow through a canister which contains the heat source modules (Brayton). The reactor power systems in the study are all based on LMCR designs, similar to SP-100. Integration of the reactor and Brayton would be accomplished through a liquid-metal to gas heat exchanger, while the Stirling systems would probably rely on liquid-metal flow across a heat pipe heat exchanger coupled to the hot-end.

The NUCOPT model permitted sensitivity analysis of several key performance parameters including peak cycle temperature, radiator areal density, and PMAD voltage. Table 1 presents the state-of-the-art for these parameters and summarizes the range considered in the study for both near term and far term applications. Near term is projected to occur in the next 10 to 15 years with reasonable technology investment; far term is projected 20 to 30 years into the future. The objective for the sensitivity analysis was to determine which parameters had the greatest influence on overall performance. A reference system consisting of $1300 \mathrm{~K}$ Brayton, $6 \mathrm{~kg} / \mathrm{m}^{2}$ radiator, and $200 \mathrm{Vac}$ distribution was selected to allow normalized comparison of technology advances.

TABLE 1. Key Performance Parameters.

\begin{tabular}{lccc}
\hline Parameter & State-of-the-Art & Near Term & Far Term \\
\hline Peak Cycle Temperature & $1144 \mathrm{~K}$ (Brayton) & $1300 \mathrm{~K}$ & $2000 \mathrm{~K}$ \\
& $925 \mathrm{~K}$ (Stirling) & & \\
Radiator Areal Density & $12 \mathrm{~kg} / \mathrm{m}^{2}$ & $6 \mathrm{~kg} / \mathrm{m}^{2}$ & $1.5 \mathrm{~kg} / \mathrm{m}^{2}$ \\
Distribution Voltage & $120 \mathrm{Vdc}$ & $200 \mathrm{Vac}$ & $5000 \mathrm{Vac}$ \\
\hline
\end{tabular}

\section{STUDY RESULTS}

The specific mass results for the "Rovers and Robotic Science" mission class are presented in Table 2 with the reference system representing $100 \%$ in each of the three power levels considered. The assumed power conversion configuration includes two engines and a shared, single sided radiator. The engines are over-sized to allow full power output in the event of an engine shutdown, and are assumed to operate nominally at partial power. A 10 meter transmission cable is included. There is a $3 \mathrm{x}$ improvement in specific mass for the reference system going from 1 to 10 kilowatts due to favorable scaling trends. The advanced supporting technologies offer only minimal mass benefits for these low power radioisotope systems, although the all-advanced case results in nearly $20 \%$ savings at $10 \mathrm{~kW}$. Stirling technology offers the greatest advantage. At the 1 kilowatt level, Stirling provides a tremendous $68 \%$ mass savings over Brayton. Even at 10 kilowatts, the Stirling system offers a considerable edge over Brayton, with $36 \%$ mass savings.

TABLE 2. Mass Comparison of Radioisotope Power Systems for Rovers and Robotic Science.

\begin{tabular}{|c|c|c|c|}
\hline System & $1 \mathrm{~kW}$ & $5 \mathrm{~kW}$ & $10 \mathrm{~kW}$ \\
\hline $1300 \mathrm{~K}$ Brayton, $6 \mathrm{~kg} / \mathrm{m}^{2}, 200$ Vac (Ref.) & $304 \mathrm{~kg} / \mathrm{kWe}$ & $127 \mathrm{~kg} / \mathrm{kWe}$ & $94.0 \mathrm{~kg} / \mathrm{kWe}$ \\
\hline Substitute $1300 \mathrm{~K}$ Stirling & $96.1 \quad(32 \%)$ & $63.5 \quad(50 \%)$ & $59.8 \quad(64 \%)$ \\
\hline 2000 K Brayton & $(94 \%)$ & $(88 \%)$ & $(85 \%)$ \\
\hline $1.5 \mathrm{~kg} / \mathrm{m}^{2}$ & $(94 \%)$ & $(90 \%)$ & $(87 \%)$ \\
\hline $5000 \mathrm{Vac}$ & $(100 \%)$ & $(100 \%)$ & $(99 \%)$ \\
\hline $2000 \mathrm{~K}$ Brayton, $1.5 \mathrm{~kg} / \mathrm{m}^{2}, 5000 \mathrm{Vac}$ & $(92 \%)$ & $(86 \%)$ & $(81 \%)$ \\
\hline
\end{tabular}


Table 3 summarizes the study results for the "Surface Outposts and Bases" mission class for three power levels ranging from 10 to 500 kilowatts. These systems are assumed to include a shaped, crew-rated reactor shield providing less than $5 \mathrm{rem} / \mathrm{yr}$ within a $90^{\circ}$ inclusion zone and less than $50 \mathrm{rem} / \mathrm{yr}$ outside the inclusion zone (Mason, 1999). The separation distance between reactor and crew is optimized based on the trade-off of shield mass and transmission line mass. The power conversion scheme consists of three engines (with two needed for full power) with each engine having its own dedicated two-sided radiator. The reference systems exhibit excellent mass scaling with increasing power level. Interestingly, the 10 kilowatt reactor power system is almost four times the mass of the comparable radioisotope system, principally due to the added shield mass. The substitution of Stirling conversion for the reactor systems provides a $14 \%$ mass benefit at 10 kilowatts, and a $15 \%$ mass penalty at 500 kilowatts relative to the reference Brayton systems. The high temperature and lightweight radiator advances provide only modest mass savings. However, high voltage distribution results in a dramatic $33 \%$ reduction in specific mass, universally across the power levels. The optimized separation distances for the 200 Vac cases were 400, 200, and 100 meters, respectively for 10,100 , and 500 kilowatts. The 5000 Vac PMAD significantly decreased the conductor mass (per unit distance) allowing the optimum separation distances to increase to 5000, 3600, and 2800 meters which translated into substantial shield mass savings.

TABLE 3. Mass Comparison of Reactor Power Systems for Surface Outposts and Bases.

\begin{tabular}{|c|c|c|c|}
\hline System & $10 \mathrm{~kW}$ & $100 \mathrm{~kW}$ & $500 \mathrm{~kW}$ \\
\hline $1300 \mathrm{~K}$ Brayton, $6 \mathrm{~kg} / \mathrm{m}^{2}, 200 \mathrm{Vac}$ (Ref.) & $341 \mathrm{~kg} / \mathrm{kWe}$ & $74.0 \mathrm{~kg} / \mathrm{kWe}$ & $38.2 \mathrm{~kg} / \mathrm{kWe}$ \\
\hline Substitute $1300 \mathrm{~K}$ Stirling & $295 \quad(86 \%)$ & $74.7 \quad(101 \%)$ & $43.9 \quad(115 \%)$ \\
\hline 2000 K Brayton & $(96 \%)$ & $(91 \%)$ & $(87 \%)$ \\
\hline $1.5 \mathrm{~kg} / \mathrm{m}^{2}$ & $(97 \%)$ & $(93 \%)$ & $(88 \%)$ \\
\hline $5000 \mathrm{Vac}$ & $(67 \%)$ & $49.5 \quad(67 \%)$ & $(66 \%)$ \\
\hline $2000 \mathrm{~K}$ Brayton, $1.5 \mathrm{~kg} / \mathrm{m}^{2}, 5000 \mathrm{Vac}$ & $(63 \%)$ & $42.2 \quad(57 \%)$ & $(50 \%)$ \\
\hline
\end{tabular}

The "Spacecraft Power and Propulsion" mission results are shown in Table 4 for power levels of 100 kilowatts, and 1 and 10 megawatts. The reactor systems include instrument-rated shielding designed to protect the control electronics located 2 meters from the core. Additional shielding would be required for piloted vehicles. The power conversion was assumed to include two engines (with one needed for full power) and a shared, single-sided radiator. The 100 kilowatt case includes 50 meters of transmission cabling while the two higher power cases include 100 meters to account for larger spacecraft configurations. The relatively low specific mass values are indicative of the economy-of-scale advantages possible with dynamic power conversion. Relative to Brayton, Stirling does not scale as well to the high power regimes. Compared to the surface power systems, specific mass is lowered by a factor of almost three due to reduced shielding, shorter cabling, and the shared radiator configuration. It is in this mission category that the benefits of high temperature materials and advanced radiators are best realized. The two advances yield very similar mass savings in each of the three power cases, with either the high temperature materials or the lightweight radiator option providing a $45 \%$ reduction in specific mass at 10 megawatts. The high voltage PMAD substitution offers a modest benefit at low power, but a sizable $27 \%$ savings at 10 megawatts.

TABLE 4. Mass Comparison of Reactor Power Systems for Spacecraft Power and Propulsion.

\begin{tabular}{|c|c|c|c|}
\hline System & $100 \mathrm{~kW}$ & $1 \mathrm{MW}$ & $10 \mathrm{MW}$ \\
\hline $1300 \mathrm{~K}$ Brayton, $6 \mathrm{~kg} / \mathrm{m}^{2}, 200 \mathrm{Vac}$ (Ref.) & $26.4 \mathrm{~kg} / \mathrm{kWe}$ & $13.3 \mathrm{~kg} / \mathrm{kWe}$ & $10.8 \mathrm{~kg} / \mathrm{kWe}$ \\
\hline Substitute $1300 \mathrm{~K}$ Stirling & $31.0 \quad(117 \%)$ & $21.8 \quad(165 \%)$ & $(192 \%)$ \\
\hline “ $\quad 2000 \mathrm{~K}$ Brayton & $21.2(80 \%)$ & $(62 \%)$ & $(55 \%)$ \\
\hline $1.5 \mathrm{~kg} / \mathrm{m}^{2}$ & $21.2(80 \%)$ & $(61 \%)$ & $(53 \%)$ \\
\hline $5000 \mathrm{Vac}$ & $24.2(92 \%)$ & $(77 \%)$ & $(73 \%)$ \\
\hline $2000 \mathrm{~K}$ Brayton, $1.5 \mathrm{~kg} / \mathrm{m}^{2}, 5000 \mathrm{Vac}$ & $17.5 \quad(67 \%)$ & $(30 \%)$ & $(18 \%)$ \\
\hline
\end{tabular}

\section{CONCLUSIONS}

An overall summary of the study results is provided in Figure 1 showing specific mass as a function of power level. For the low power radioisotope systems, Stirling is the obvious choice from a mass perspective. The application of advanced technology to the Brayton radioisotope systems has minimal effect. The mass cross-over point (in which 
Brayton would be lower mass than Stirling) is probably in the 15 to 20 kilowatt range, which is beyond the practicle limit for the radioisotope systems. The high power spacecraft reactor system results indicate Brayton as the clear favorite. Advanced high temperature materials, lightweight radiators, and high voltage PMAD have a significant impact resulting in a specific mass of $2 \mathrm{~kg} / \mathrm{kWe}$ at 10 megawatts with the all-advanced system. The cross-over point for the spacecraft mission class is in the 30 to 40 kilowatt range, above which Brayton offers the lower mass option. The preferred technology for the surface reactor systems is less apparent, with Stirling slightly better below 50 kilowatts and the reference Brayton preferred above 50 kilowatts. In this application, the crew-rated reactor shield dominates system mass. The use of high voltage PMAD provides a universal benefit, enabling longer transmission cables and increased separation distance to reduce shield mass.

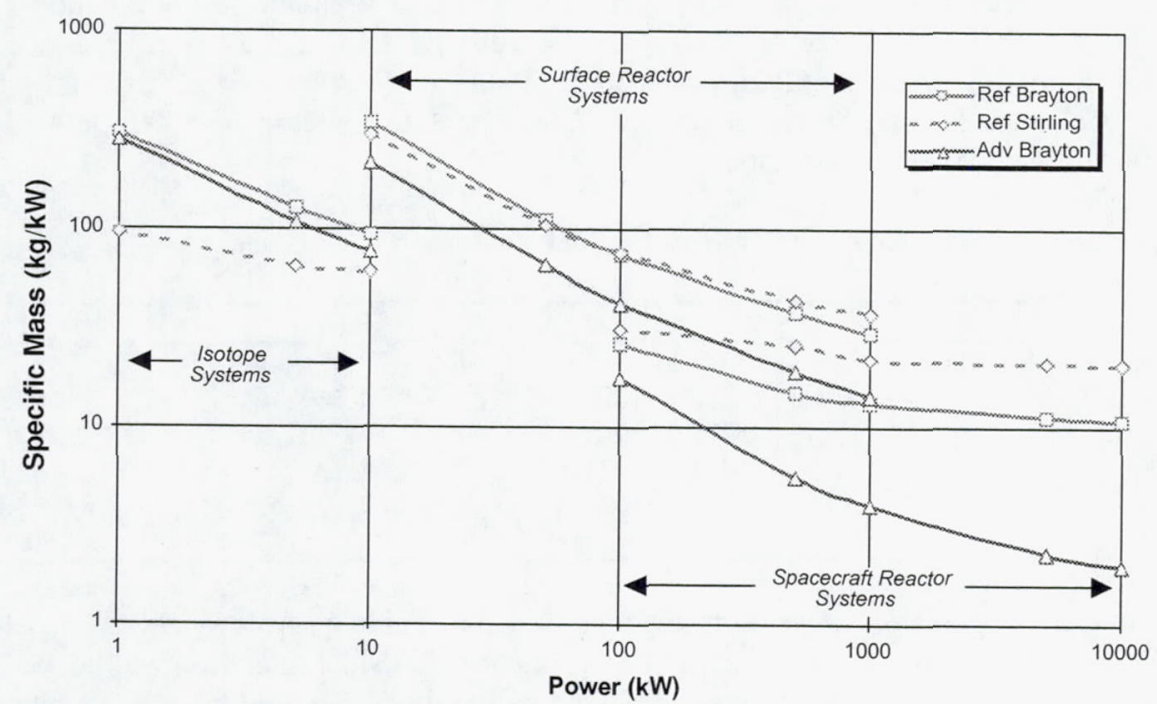

FIGURE 1. Summary of Specific Mass Projections for Brayton and Stirling Power Systems

Of course, there are factors other than specific mass which should be considered in selecting the power conversion technology, particularly cost. Considerable cost savings would be possible if a common engine module could be developed for multiple applications. For example, a $25 \mathrm{~kW}$ module could be used in a cluster of two for outpost reactors, a cluster of four for robotic NEP, and a cluster of eight for permanent base reactor systems. Cost savings could also be realized through an evolutionary development approach. Early missions would utilize lower power systems with minimal advanced technology. As the missions become more elaborate, higher power systems with greater technology advances could be introduced that maintain heritage with the previous designs.

\section{REFERENCES}

Davis, J.E., "Design and Fabrication of the Brayton Rotating Unit," NASA/CR-1870, March 1972.

Dochet, George, "SPDE/SPRE Final Summary Report," NASA/CR-187086, September 1993.

Dhar, Manmohan, "Stirling Space Engine Program, Volume 1-Final Report," NASA/CR-1999-209164, August 1999.

Marshall, A.C., and Gallup, D.R., "RSMASS-D: Reactor and Shield Mass Minimization Models," s $^{\text {th }}$ Symposium on Space Nuclear Power Systems Proceedings, 1991.

Mason, Lee S., "Surface Nuclear Power for Human Mars Missions,” NASA/TM-1999-208894, January 1999.

McCormick, J.E., "Brayton Isotope Power System Phase 1 Final Report," Prepared for the Department of Energy, Report Number 31-2919, July 1978.

Metcalf, Kenneth J., "Lunar PMAD Technology Assessment," NASA/CR-189225, February 1992.

Shaltens, Richard S. and Mason, Lee S., "800 Hours of Operational Experience From a 2 kWe Solar Dynamic System," NASA/TM-1999-208840, January 1999.

Staff of the Solar Dynamic Power Systems Branch, "Solar Dynamic Power System Development for Space Station Freedom," NASA/RP-1310, July 1993.

Thieme, Lanny G. and Schreiber, Jeffrey G., "NASA GRC Technology Development Project for a Stirling Radioisotope Power System," NASA/TM-2000-210246, July 2000. 


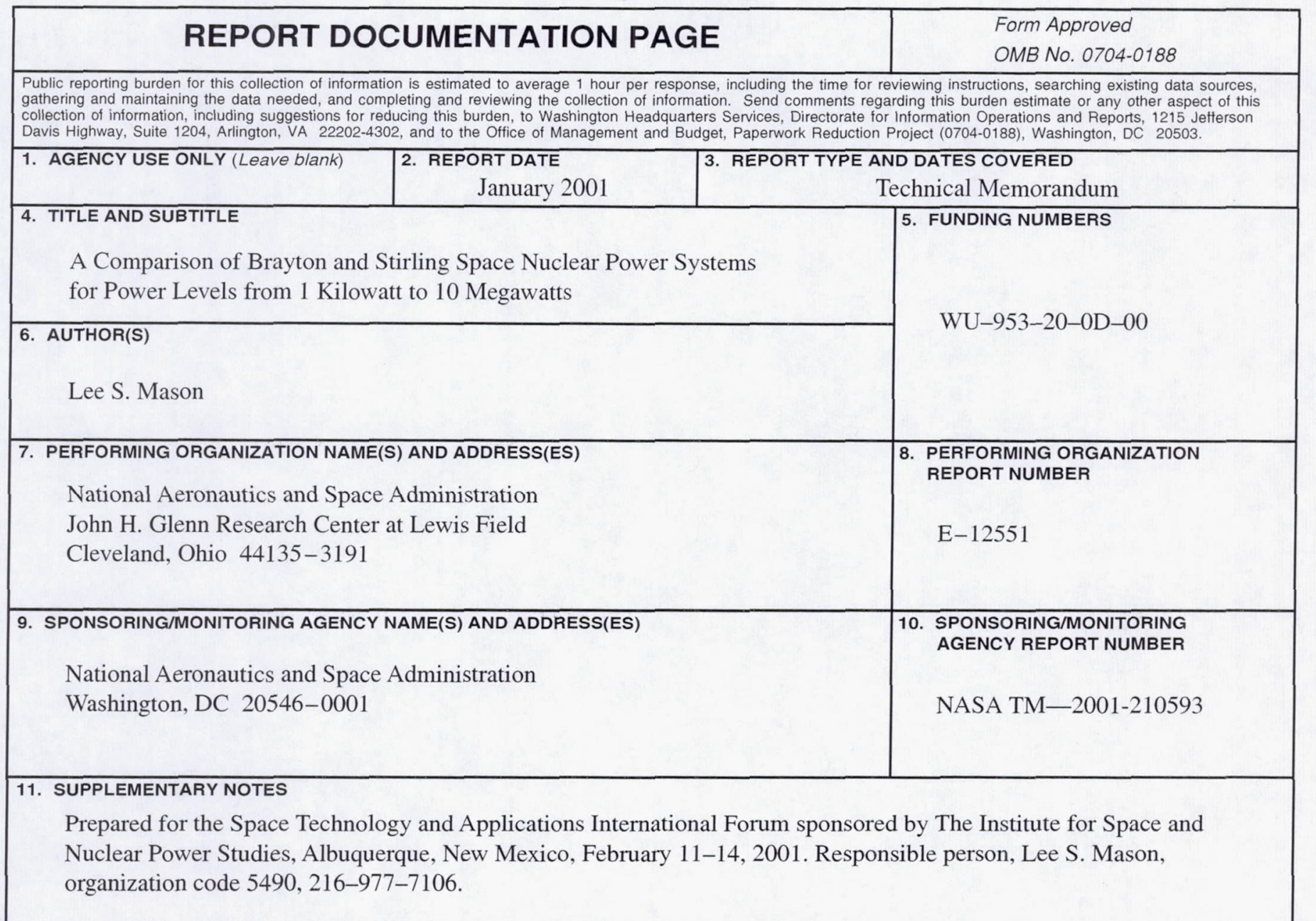

12a. DISTRIBUTION/AVAILABILITY STATEMENT

12b. DISTRIBUTION CODE

Unclassified - Unlimited

Subject Category: 20

Distribution: Nonstandard

Available electronically at http://gltrs.grc.nasa.gov/GLTRS

This publication is available from the NASA Center for AeroSpace Information, 301-621-0390.

13. ABSTRACT (Maximum 200 words)

An analytical study was conducted to assess the performance and mass of Brayton and Stirling nuclear power systems for a wide range of future NASA space exploration missions. The power levels and design concepts were based on three different mission classes. Isotope systems, with power levels from 1 to $10 \mathrm{~kW}$, were considered for planetary surface rovers and robotic science. Reactor power systems for planetary surface outposts and bases were evaluated from 10 to $500 \mathrm{~kW}$. Finally, reactor power systems in the range from $100 \mathrm{~kW}$ to $10 \mathrm{~mW}$ were assessed for advanced propulsion applications. The analysis also examined the effect of advanced component technology on system performance. The advanced technologies included high temperature materials, lightweight radiators, and high voltage power management and distribution.

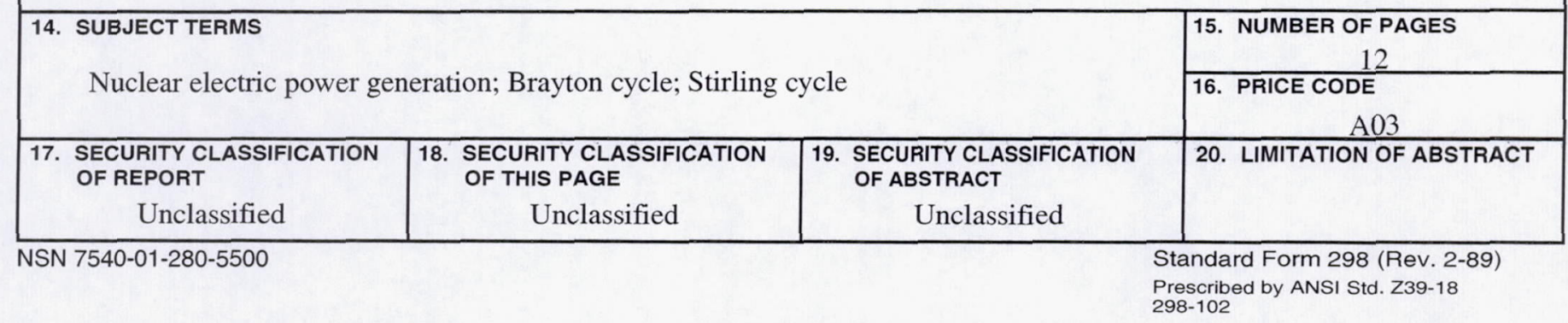

